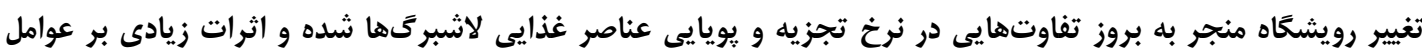

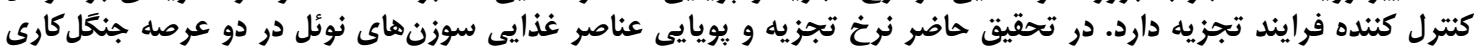

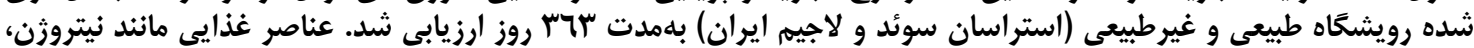

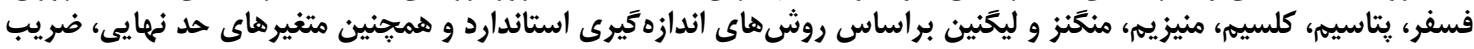

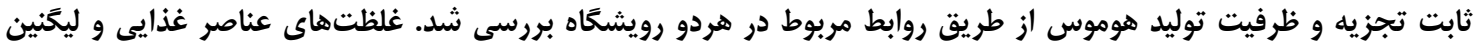

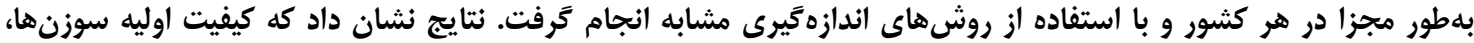

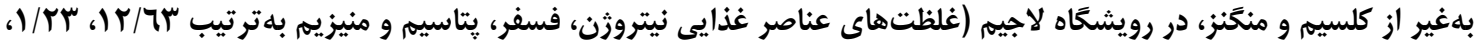

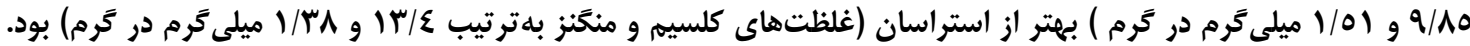

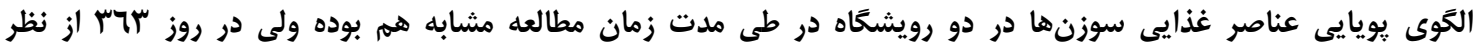

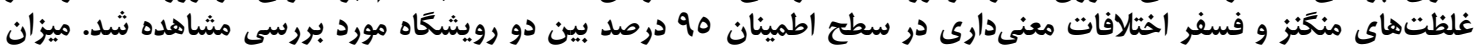

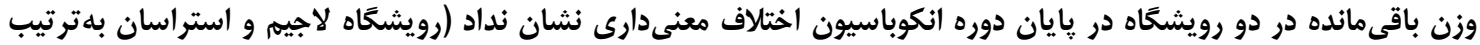

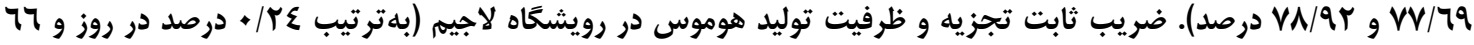

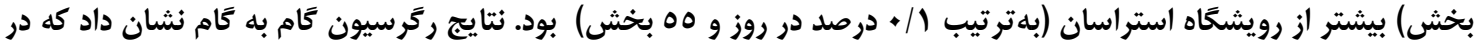

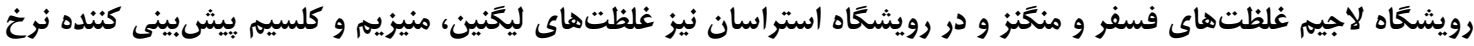

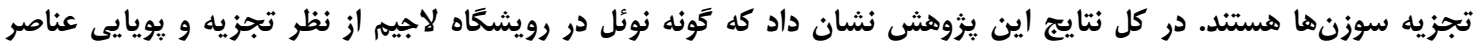

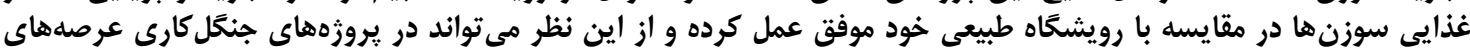
كوهستانى هير كانى مورد استفاده قرار تيرد.

وازههاى كليدى: تغيير رويشَاه، جنكَلهاى سوزنىبركى شمالى، كيفيت لاشبرتى، نرخ تجزيه، نوئل

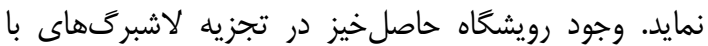

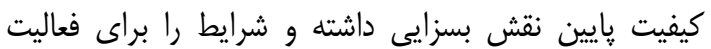

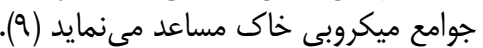

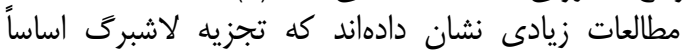

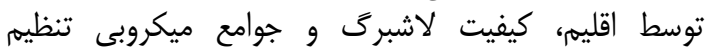

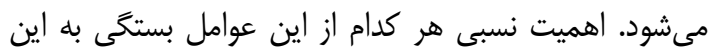

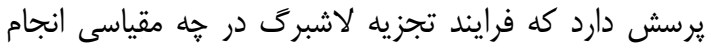

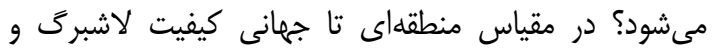

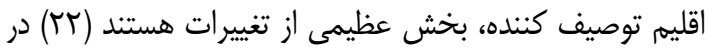

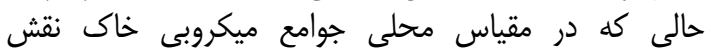

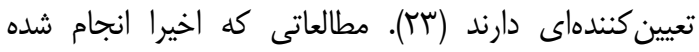

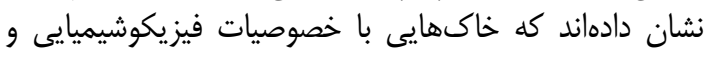

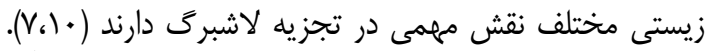

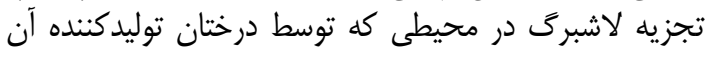

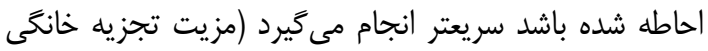

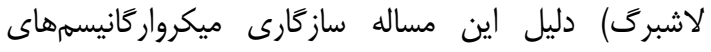

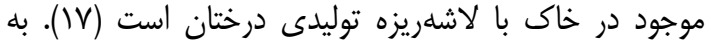

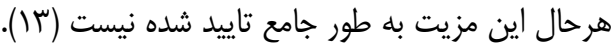

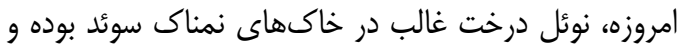
داراى ارزش اقتصادى بالايى است. نوئل دائل داراى سيستم ريشهاى سطحى بوده و لايه ضخيمى از مواد آلى را در خاك
مقدمه

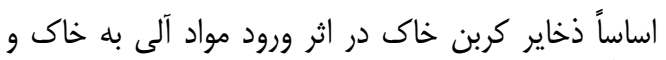

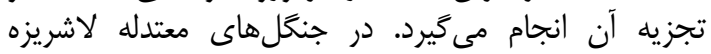

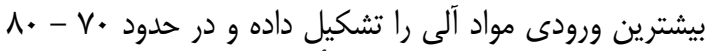

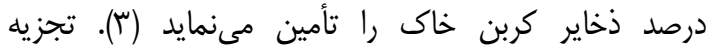

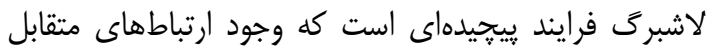

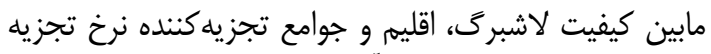

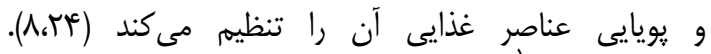

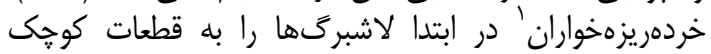

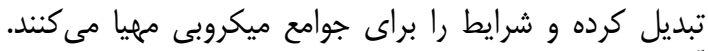

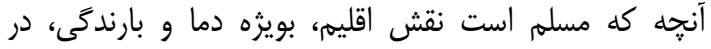

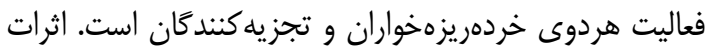

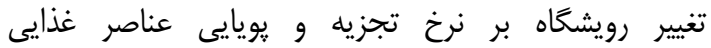

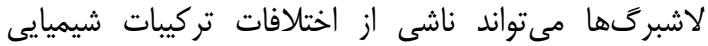

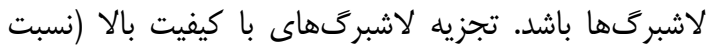

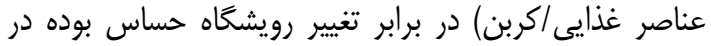

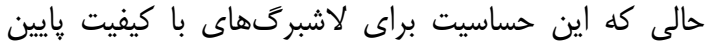

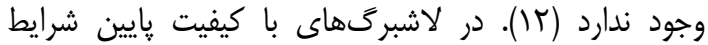

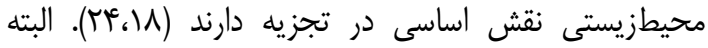

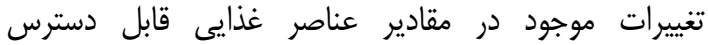
لاشبرگها نيز مىتواند اثر تغيير رويشگاه جنخلى را كنترل 
در اين تحقيق فرايند تجزيه و يويايى عناصر غذايى

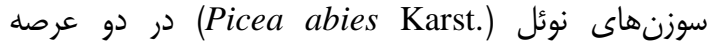

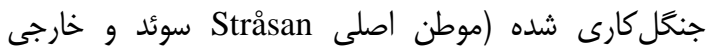

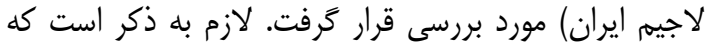

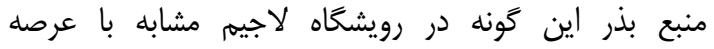

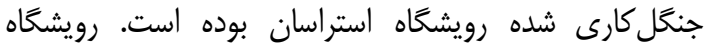
استراسان در قسمت مركزى سوئد واقع شده است. از رال سال 1901 جنگل كارى نوئل (Picea abies Karst.

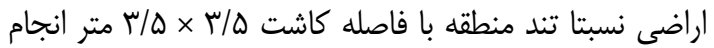

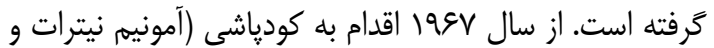

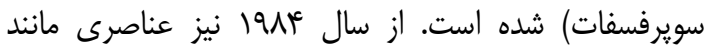

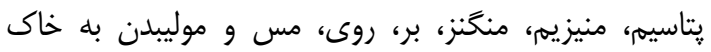

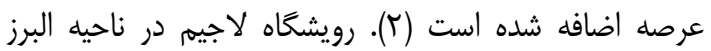

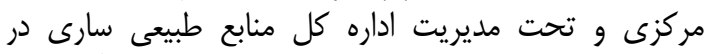

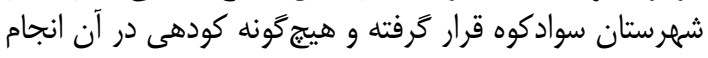

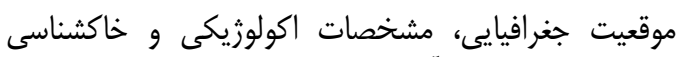
رويشگاهها در جدول آميت آمده است (Y.IV).
تشكيل مى دهد. اين درخت موجب اسيدى شدن خاك مى إشود

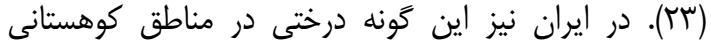

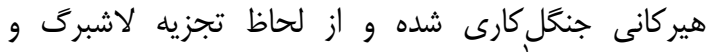

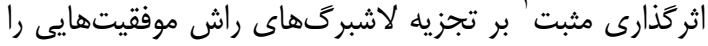

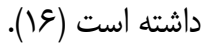

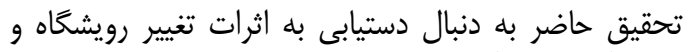

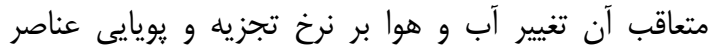

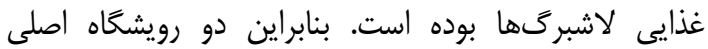

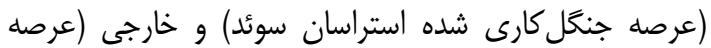

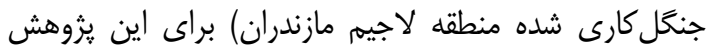

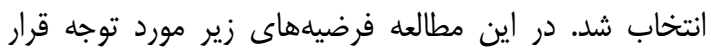

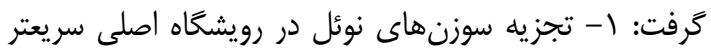

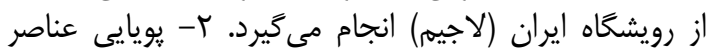

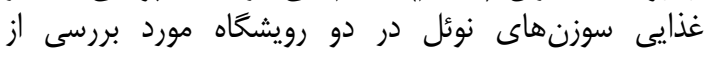
الخوهاى مشابهى تبعيت مىنمائ نوئ درئ

\section{مواد و روشها منطقه مورد بر روسى}

Table 1. Ecological and Edaphical characteristics of studied stands

جدول ا- مشخصات اكولوزيكى و خاكشناسى رويشخاههاى مورد بررسى

\begin{tabular}{|c|c|c|}
\hline استراسان & لاجيم & نام رويشگاه \\
\hline 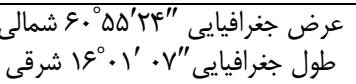 & 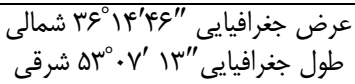 & مختصات جغرافيايى \\
\hline ra. & Q 90 & ارتفاع از سطح دريا \\
\hline$V E \Delta$ & $\Lambda V \Lambda / \iota^{c}$ & ميانگَين بارندگى ساليانه (ميلىمتر) \\
\hline$r / l$ & $14 / 9$ & ميانكَين دماى ساليانه (سانتى گراد) \\
\hline 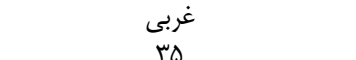 & شمالى الى & شهت عمومىى (\%) \\
\hline \&) & द. & سن سيب سموسى (ر) \\
\hline$\Delta / 1$ & $\Delta / V$ & اسيديته خاى \\
\hline رسى - شنى & 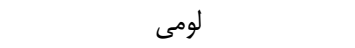 & بافت خاك \\
\hline ي يدزول & راندزين - كوالسيمورف & نوع هوموس \\
\hline
\end{tabular}

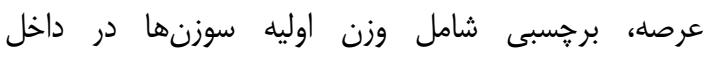

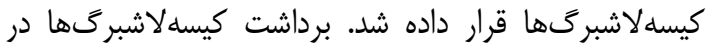

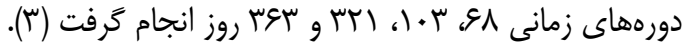

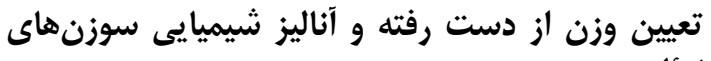

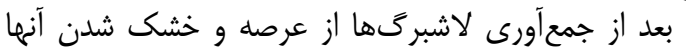

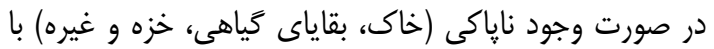

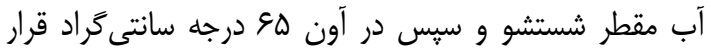

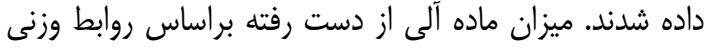

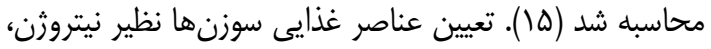

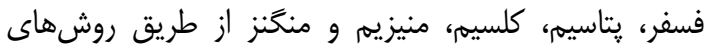

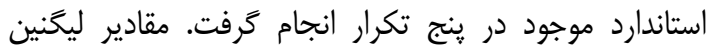

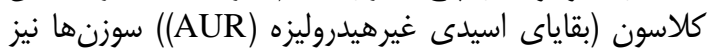

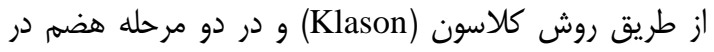

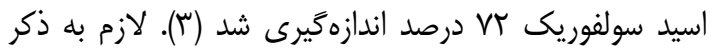

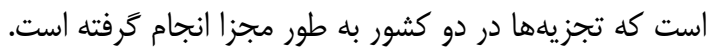

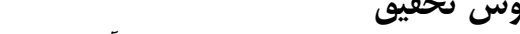
روش انجام تحقيق و طراحى آزمايش در درو دو رويشگاه

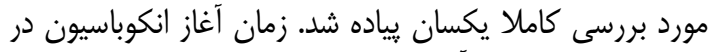

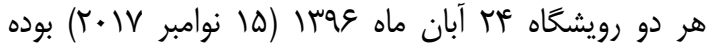

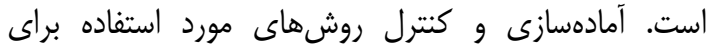

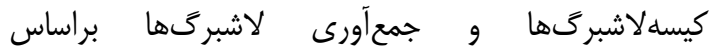

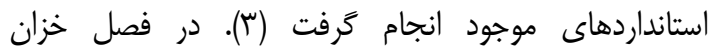

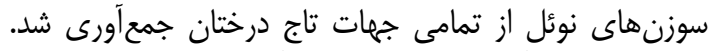

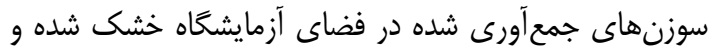

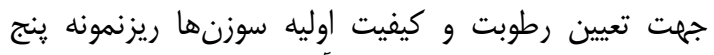

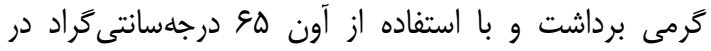

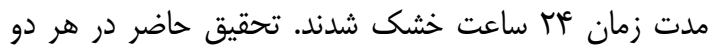

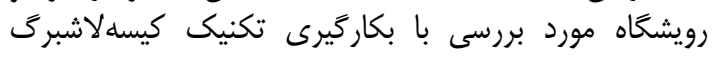

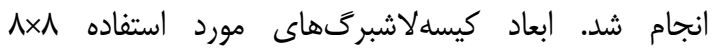

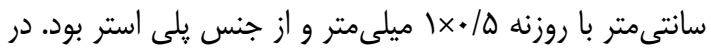

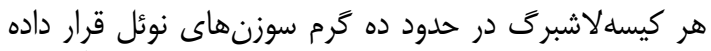

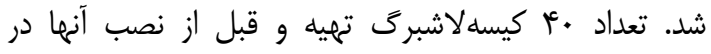


آلى از دست رفته، بلهنوان متغير وابسته، از ركرسيون كام بهام إنها كام استفاده شد. كليه آزمونهاى آمارئ آمارى با استفاده از نرمافزار SPSS ver. 22

\section{نتايج و بحث} كيفيت شيميايى لاشبركَها در ابتدا و انتهاى زمان بر اساس نتايج مشخص شد كه غلظتهاى عناصر غذايى

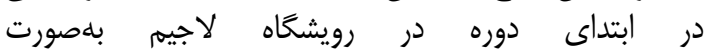
و و در رويشگاه استراسان نيز به صورت Ca>N>Mn>K>Mg>P بود كه در هردو رويشگاه

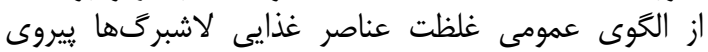

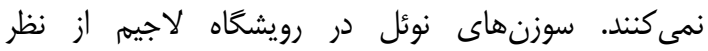

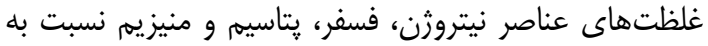

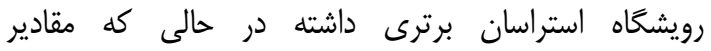

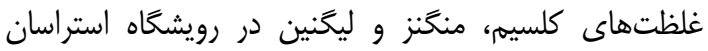

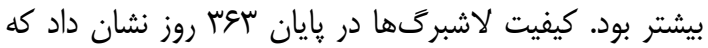

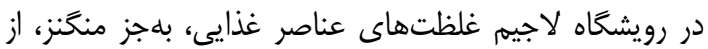

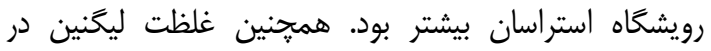

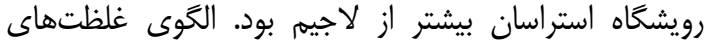

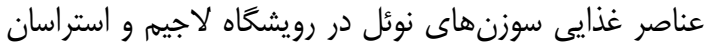

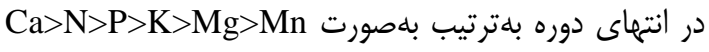

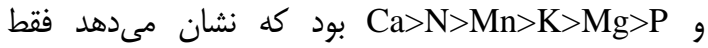
مقادير غلظتهاى منگَنز و فسفر در دو رويشگاه متفاوت بودند

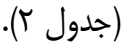

يروتكل انجام آزمايشات (نظير نيتروزن روش كجدال، فسفر از طريق اسيكتروفتومتر و غيره) كاملا يكسان بوده است.

ضريب ثابت تجزيه، حد نهايیى تجزيه لاشبركى و

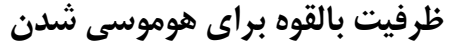

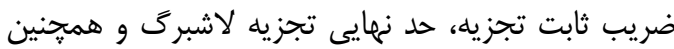

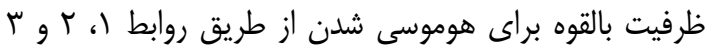
محاسبه شدند (1). (1). $\mathrm{M}_{\mathrm{t}}=\mathrm{M}_{0} \cdot \mathrm{e}^{-k t}$ رابطه (1)

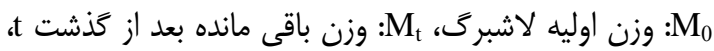

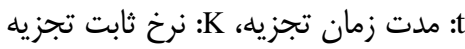
$-k t / m$

$\mathrm{L}=\mathrm{m}(1-\mathrm{e} \quad)$

(T) رابطه (T)

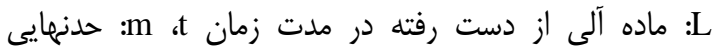

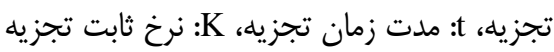

$\mathrm{LH}=(100-$ Limit Value $) / 100$

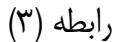

LH

تجزيه و تحليل دادهها

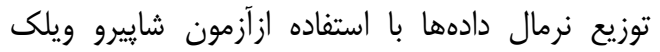

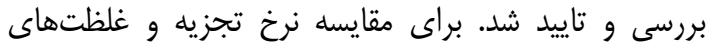

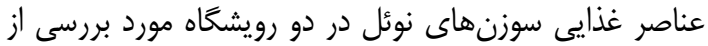

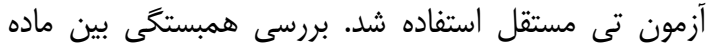

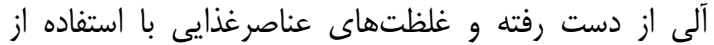

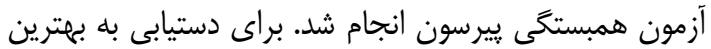

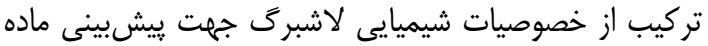

جدول r- كيفيت شيميايى سوزن هاى نوئل در ابتدا و انتهاى زمان بررسى در دو رويشگاه لاجيم و استراسان (ميلىگرم در گرم) Table 2. Initial chemical of Norway spruce needles in the first and end time of Incubation time in two stands of Lajim and Stråsan $(\mathrm{mg} / \mathrm{g})$

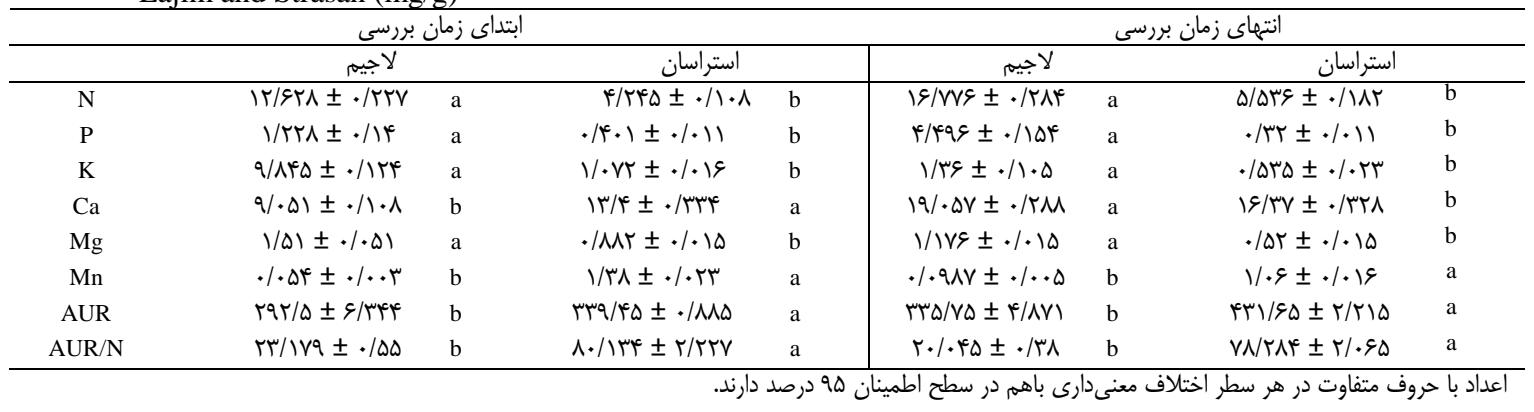

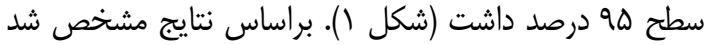

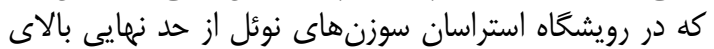

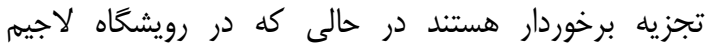

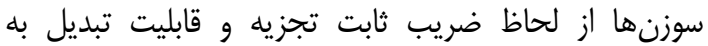

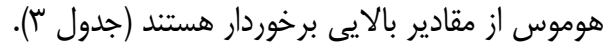

ماده آلى از دست رفته، حد نهايیى تجزيه، ضريب ثابت

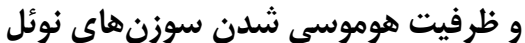

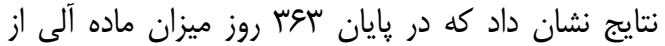

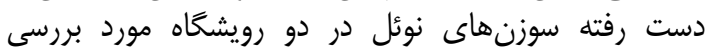

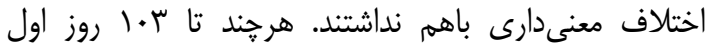

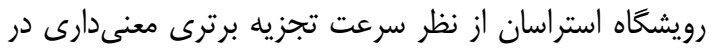




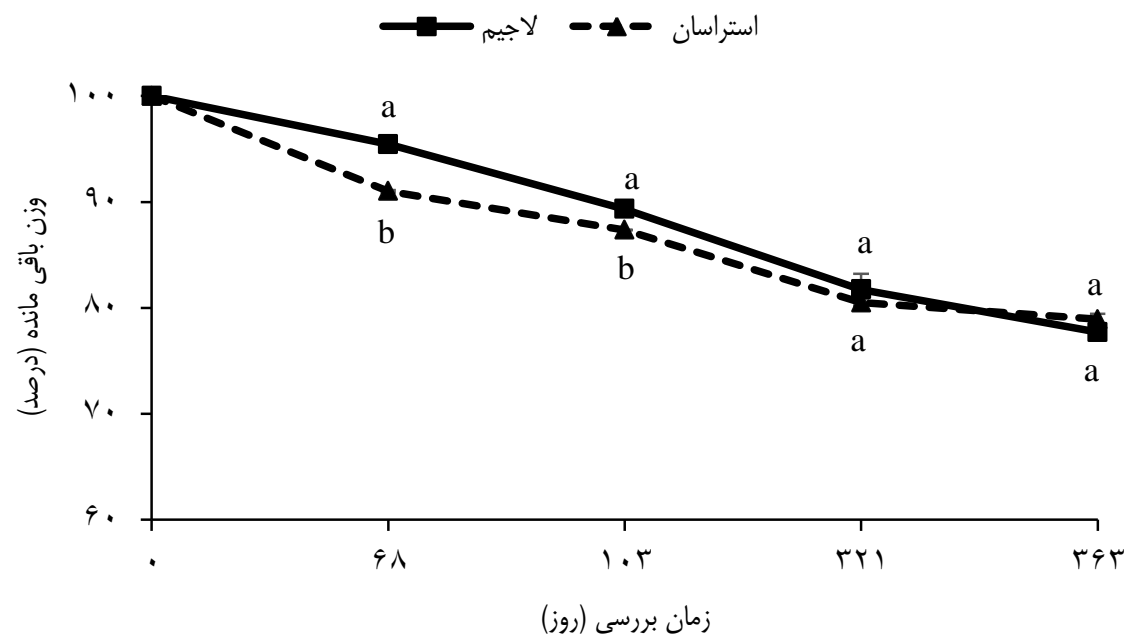

شكل ا- وزن باقىمانده (درصد) سوزنهاى نوئل در دو رويشخاه لاجيهم و استراسان

Figure 1. Remaining weight (\%) of Norway spruce needles in two stands of Lajim and Stråsan

جدول ب- حد نهايى، ضريب ثابت تجزيه و ظرفيت هوموسى شدن سوزن هاى نوئل در دو رويشعاه مورد برسى Table 3. Limit value, decomposition constant coefficient and humisification potential of Norway spruce needles in

\begin{tabular}{|c|c|c|c|c|c|}
\hline \multicolumn{3}{|c|}{ لاجيم } & \multicolumn{3}{|c|}{ استراسان } \\
\hline حد نهايى تجزيه & ضريب ثابت تجزيه & ظرفيت هوموسى شدن & حد نهايى تجزيه & ضريب ثابت تجزيه & ظرفيت هوموسى شدن \\
\hline$\Gamma \mu / 9 q \pm 1 / \Lambda \Delta$ & $. / T^{f} \pm \cdot / 11$ & $. / 99 \mu \pm . / .11$ & $\left.F \Delta / \Gamma^{\top} \pm \Gamma / \Delta\right)^{F}$ & $\cdot / / \pm \cdot / \mu \gamma^{c}$ & $. / \Delta)^{E} V \pm .1 .9 Q$ \\
\hline
\end{tabular}

غير از غلظت اوليه در بقيه زمانهاى بررسى مقادير غلظت

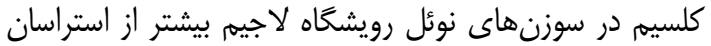

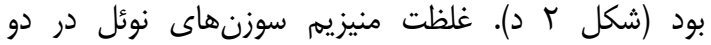

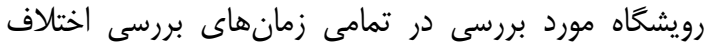

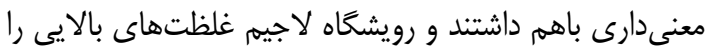

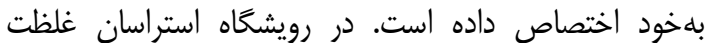

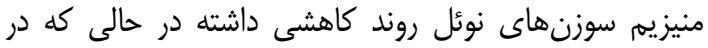

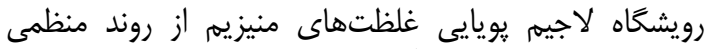

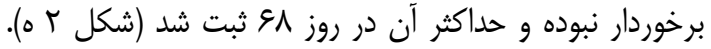

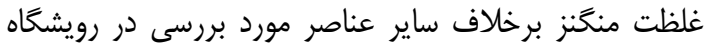

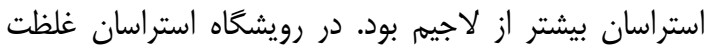

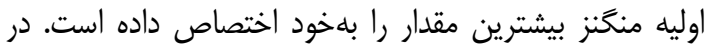

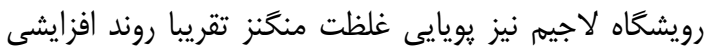

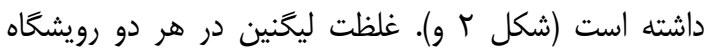

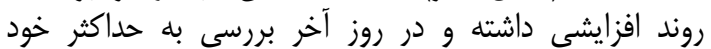

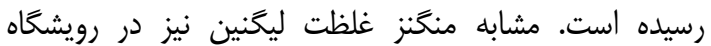
استراسان بيشتر از رويشآ لاجيم بود (شكل ؟ ز ز).

\section{يويايى عناصر غذايى سوزن هاى نوئل}

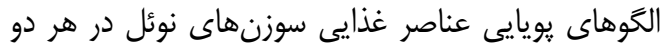

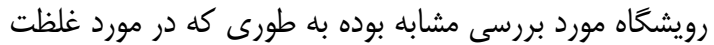

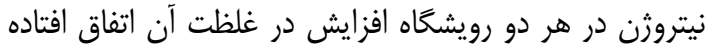

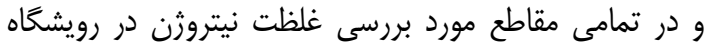

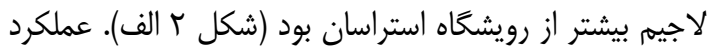

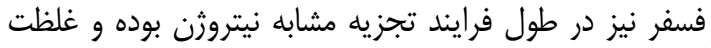

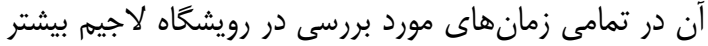

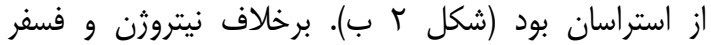

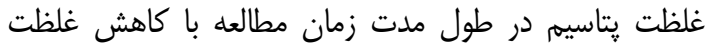

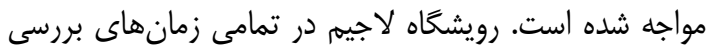

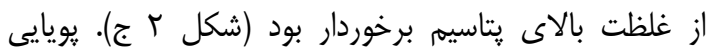

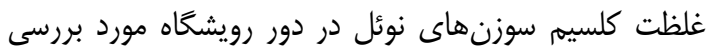

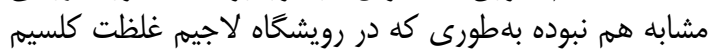

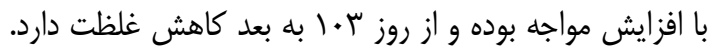

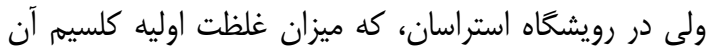

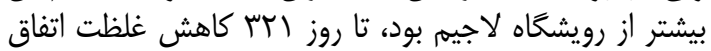

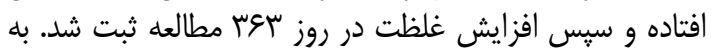




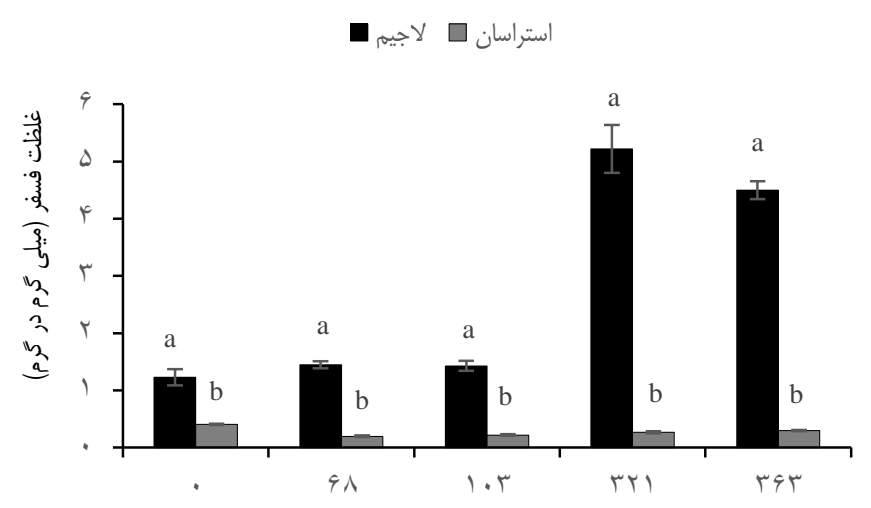

زمان بررسى (روز)

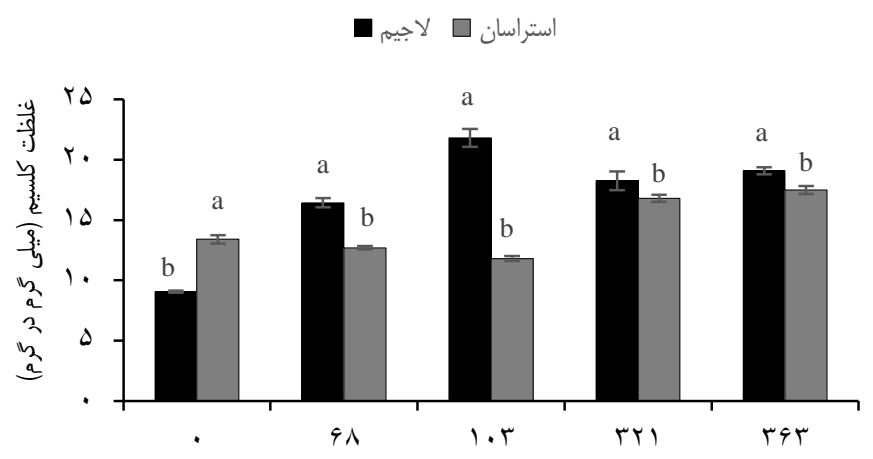

زمان بررسى (روز)

$$
\text { ص استراسان ص لاجيم }
$$

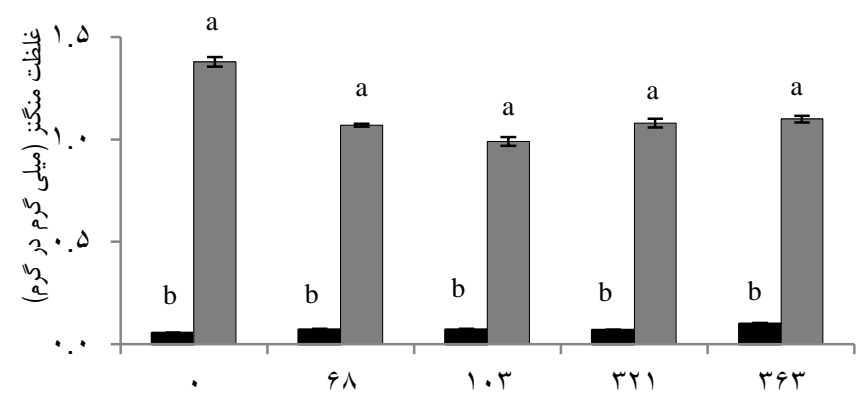

زمان بررسى (روز)

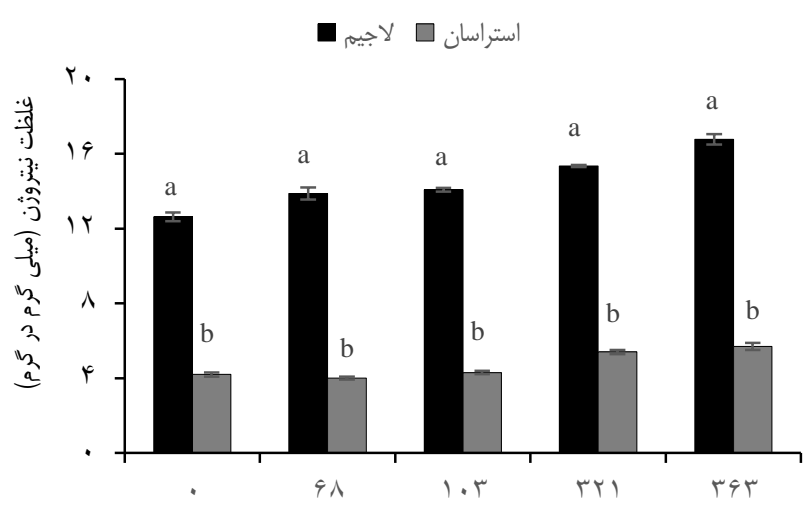

زمان بررسى (روز)

ج

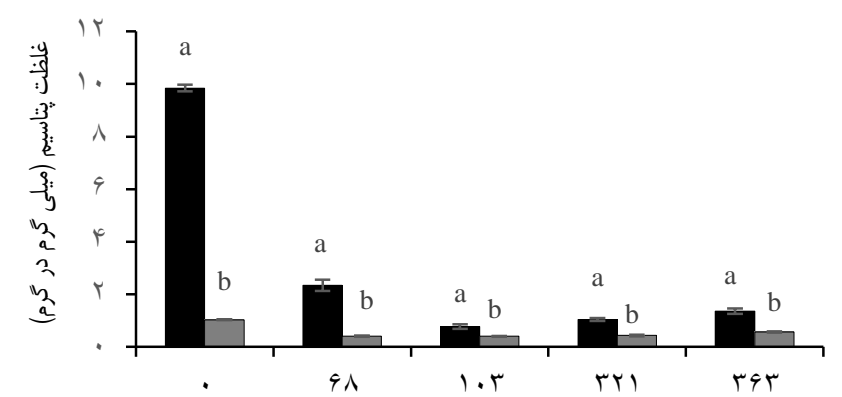

زمان بررسى (روز)

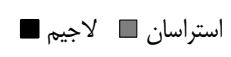

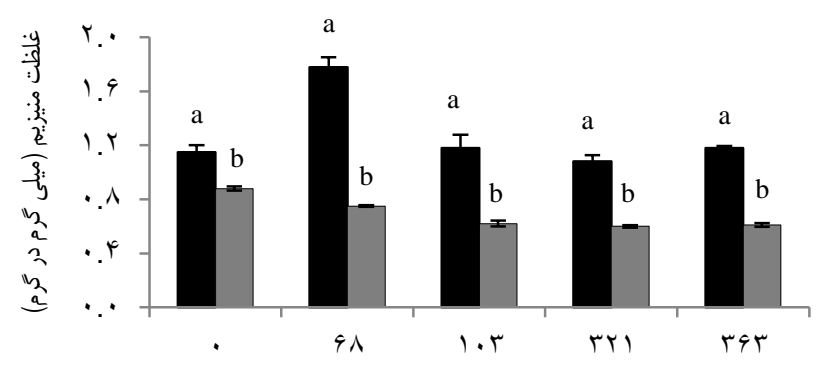

زمان بررسى (روز)

شكل r- يويايى عناصر غذايى و ليكنين سوزنهاى نوئل در دو رويشكاه لاجيهم و استراسان

Figure 2. Nutrients and lignin dynamics of Norway spruce needles in two stands of Lajim and Stråsan 


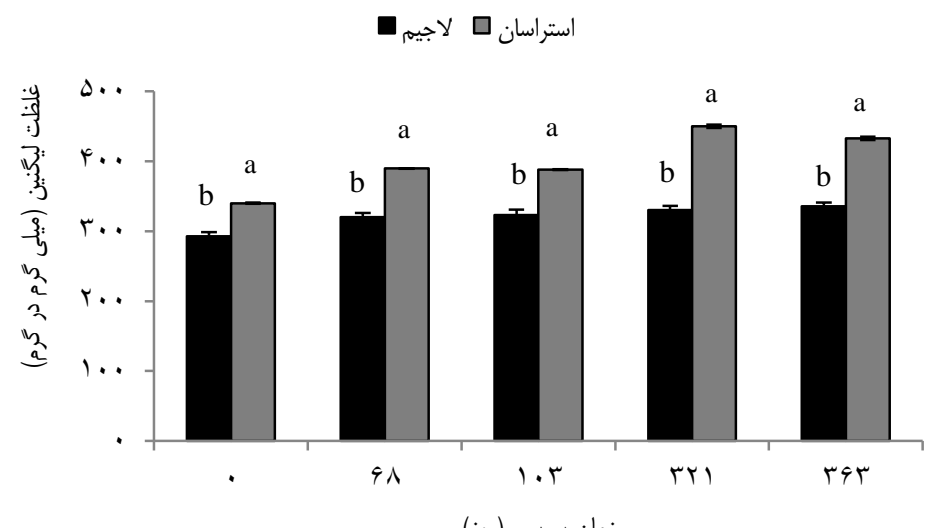

زمان بررسى (روز)

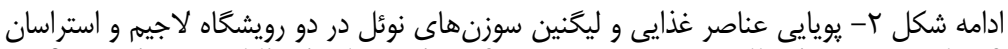

Continued Figure 2. Nutrients and lignin dynamics of Norway spruce needles in two stands of Lajim and Stråsan

سطح ینج درصد دارد (جدول غأ). در رويشگاه استراسان غلظت

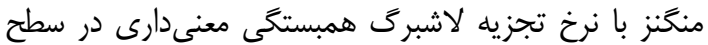

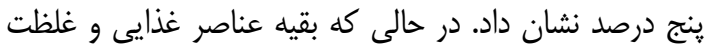

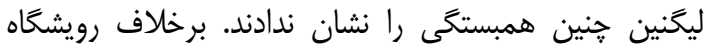

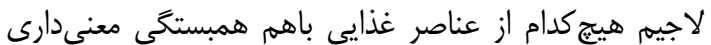

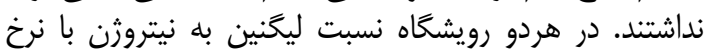

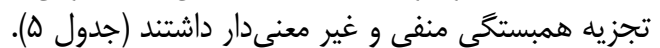

همبستكَى بين ماده آلى از دست رفته با غلظتهاي

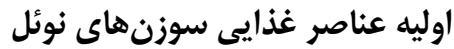

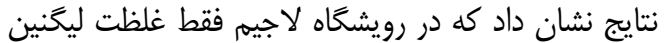

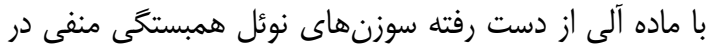

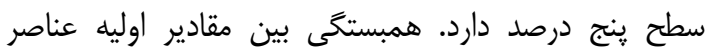

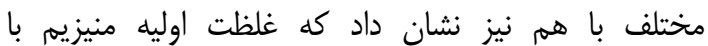

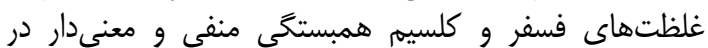

جدول أ- همبستخى بين نرخ تجزيه سوزنهاى نوئل و مقادير اوليه غلظتهاى عناصر غذايى در رويشگاه لاجيم Table 4. Correlation between mass loss of Norway spruce needles and initial concentrations of nutrients in Lajim

\begin{tabular}{|c|c|c|c|c|c|c|c|c|c|}
\hline & Mass loss & $\mathrm{N}$ & $P$ & $\mathrm{~K}$ & $\mathrm{Mg}$ & $\mathrm{Ca}$ & $\mathrm{Mn}$ & AUR & AUR/N \\
\hline Mass loss & 1 & & & & & & & & \\
\hline $\mathrm{N}$ & . $/ \cdot r F$ & 1 & & & & & & & \\
\hline $\mathrm{P}$ & .1991 & אזץ/. & 1 & & & & & & \\
\hline $\mathrm{K}$ & . & $-\cdot / 9 \cdot \Delta$ & שצqא. & 1 & & & & & \\
\hline $\mathrm{Mg}$ & - . /vat &.$- / N K \Lambda$ &.$- / 9 V r^{* *}$ &.$- / 8 \Lambda$. & 1 & & & & \\
\hline $\mathrm{Ca}$ & . /ArQ & ואו/. - & $\cdot / \mathrm{A} \wedge$ & $\cdot / \wedge p q$ &.$- / 98 \varphi^{4 *}$ & 1 & & & \\
\hline Mn & ./^q. & שFא. & - . & س r & . & $-\cdot / \Delta T \Lambda$ & 1 & & \\
\hline AUR & $-\cdot / 9 \Delta \rho^{\prime \prime}$ & ./rq४ & $\cdot / \& \wedge \Delta$ &.$/ 4 q \varepsilon$ & $-\cdot / V K F$ &.$/ 9 M M$ & $-\cdot|\Lambda \Delta|$ & 1 & \\
\hline AUR/N &.$- / / 99$ &.$- / Q \wedge \gamma^{\prime \prime}$ & . /VAD & .1011 &.$- / \Delta F q$ &.$/ 914$ & - . MET & א & 1 \\
\hline
\end{tabular}

جدول ه- همبستخى بين نرخ تجزيه سوزنهاى نوئل با مقادير اوليه غلظتهاى عناصر غذايى در رويشگاه استراسان Table 5. Correlation between mass loss of Norway spruce needles and initial concentrations of nutrients in Stråsan

\begin{tabular}{|c|c|c|c|c|c|c|c|c|c|}
\hline & Mass loss & $\mathrm{N}$ & $\mathrm{P}$ & $\mathrm{K}$ & $\mathrm{Mg}$ & $\mathrm{Ca}$ & $\mathrm{Mn}$ & AUR & AUR/N \\
\hline Mass loss & 1 & & & & & & & & \\
\hline $\mathrm{N}$ & $\cdot / \Gamma \Delta \mid$ & 1 & & & & & & & \\
\hline $\mathrm{P}$ & . &.$/ \mu q$. & 1 & & & & & & \\
\hline $\mathrm{K}$ &.$/ 8 \cdot T$ & - - &.$- / 49 V$ & 1 & & & & & \\
\hline $\mathrm{Mg}$ &.$- / 91 \%$ & $\cdot / \cdot V$ & $\cdot|90|$ & . & 1 & & & & \\
\hline $\mathrm{Ca}$ & $\cdot /$ AV & $-\cdot / V Q T$ & שאג|. - &.$/ 994$ & פTRT - - & 1 & & & \\
\hline $\mathrm{Mn}$ & . /qY४" &.$/ F V \Delta$ & $-\cdot / T V K$ &.$- / 499$ & $-\cdot /$ AVG & $-\cdot /$ VV & 1 & & \\
\hline AUR & $-\cdot / \Lambda \mathrm{r}$. & $-\cdot / \mathrm{VV} \cdot$ & . / $1 F q$ & 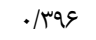 & . /9Yq & $\cdot / r \cdot r$ & r - - & 1 & \\
\hline AUR/N & $-\cdot\left|V^{*}\right|$ & $-\cdot / \Lambda F V$ & . /9TA & GT/A & $\cdot / \Delta \wedge 9$ &.$/ 4 \wedge 9$ & $-\cdot / \Lambda \uparrow \Lambda$ & $\cdot / 9 \wedge \mathrm{V}^{*}$ & 1 \\
\hline
\end{tabular}




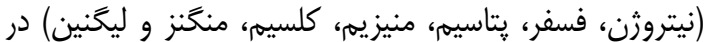

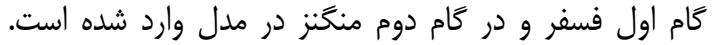

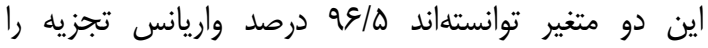
توصيف نمايند (جدول ع).
ييشبينى ماده آلى از دست رفته سوزنها از طريق تر كيبات شيميايیى اوليه براساس نتايج رگرسيون گام به كام مشخيات رويشگاه لاجيم از بين تركيبات شيميايى اوليه لاشبرى

جدول و- اطلاعات ركرسيون كام به كام متغير تابع (درصد ماده آلى از دست رفته) و متغيرهاى توصيف كننده (نيتروثن، فسفر، يتاسيه، منيزيم،

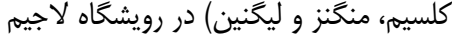

Table 6. Step regression data of dependent variable (Mass loss \%) and qualifier variables (N, P, K, Mg, Ca, Mn and Lignin) in Lajim stand

\begin{tabular}{|c|c|c|c|c|c|c|c|}
\hline متغير وابسته & مدل & 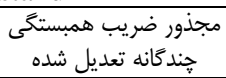 & درجه أزادى & درجه آزادى باقىمانده & 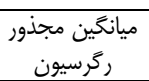 & ميانغين مجذور & معنىدارى \\
\hline ماده آلى از دست & $P$ & $\cdot / \wedge 9$. & & & $9 \Delta \mathrm{DV} / \mathrm{r} \cdot 1$ & $v / \wedge \Gamma \Delta$ &.$\%$ \\
\hline $\begin{array}{l}\text { رفته } \\
\text { (\%) }\end{array}$ & $\mathrm{Mn}$ & $\cdot / 9 \& 0$ & 1 & if & TIV/TAI & $5 / \uparrow 99$ &.$\ldots$ \\
\hline
\end{tabular}

غلظت منگَنز در رويشگاه استراسان برخلاف رويشگاه لاجيهم

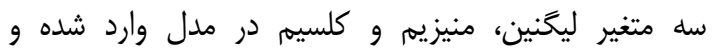

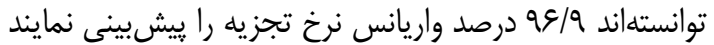

بنابراين معادله رگرسيونى رويشگاه لاجيهم به صورت زير

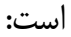

$\mathrm{Y}=-0.568+3.968 \mathrm{X}_{1}+167.740 \mathrm{X}_{2}$

=X ماده آلى از دست رفته (\%) =Y

جدول V- اطلاعات ركرسيون كَام به كام متغير تابع (درصد ماده آلى از دست رفته) و متغيرهاى توصيف كننده (نيتروزن، فسفر، يتاسيه، منيزيم،

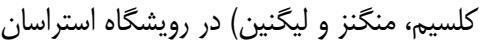

Table 7. Step regression data of dependent variable (Mass loss \%) and qualifier variables (N, P, K, Mg, Ca, Mn and Lignin) in Stråsan stand

\begin{tabular}{|c|c|c|c|c|c|c|c|}
\hline متغير وابسته & 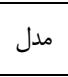 & مجذور ضرانه تعديب همبستخى شده & 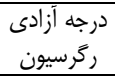 & درجه آزادى باقىمانده & ميانخين مجذور ريون & ميانخين مجذور ريون & معنى دارى \\
\hline ماده آلى از دست & AUR & $\cdot / 9 \cdot r$ & & & $\mid c 41 / 8 \wedge 9$ & $\Gamma / \backslash \Delta \varphi$ &.$/ \cdots$ \\
\hline رفته & $\mathrm{Mg}$ &.$/ 909$ & 1 & 15 & 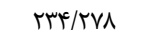 & אسז/1 & $\cdot 1 \ldots$ \\
\hline
\end{tabular}

مواد معدنى خاك، سنَ مادر و هوموس از عوامل تاثير خذار در

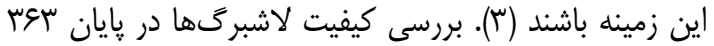

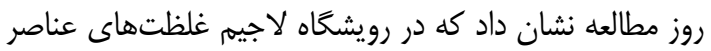

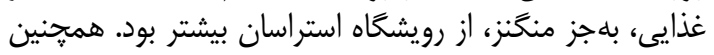

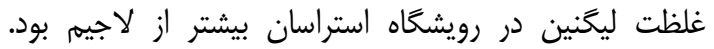

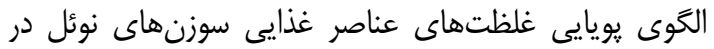

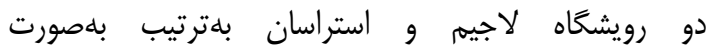
Ca>N>Mn>K>Mg>P , $\mathrm{Ca}>\mathrm{N}>\mathrm{P}>\mathrm{K}>\mathrm{Mg}>\mathrm{Mn}$ همان طورى كه مشاهده مىشود با نزديك شدن به مرحله آخر

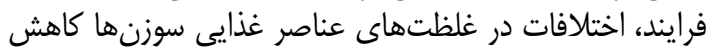

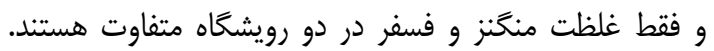

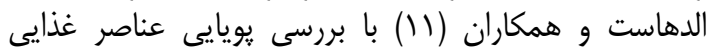

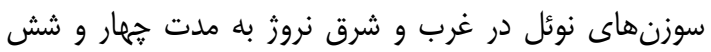

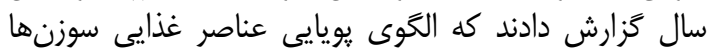
بلاصورت Ca>K>Mg >P>Mn>N است. در هردو رويشعاه لاجيم و استراسان، برخلاف نتايج الدهاست و همكاران (1)،

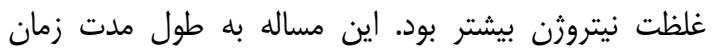

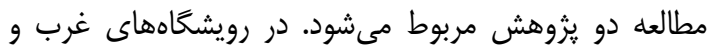

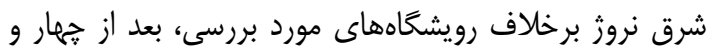

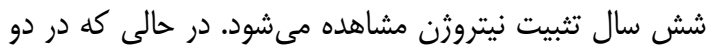

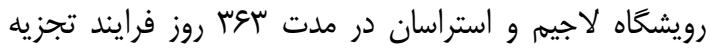

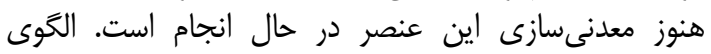

بنابراين معادله رگرسيونى رويشگاه استراسان به صورت زير

$\mathrm{Y}=-96.592+0.279 \mathrm{X}_{1}-19.3 \mathrm{X}_{2}-0.8 \mathrm{X}_{3}$

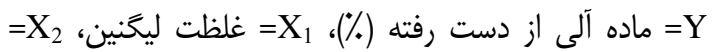

غلظت منيزيم، X X

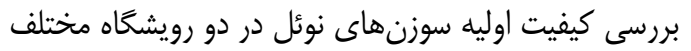
نشان داد كه از نظر غلظتهاى كار عناصر غذايى اختلافاتى وجود

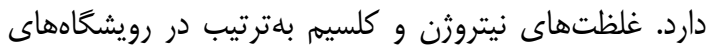

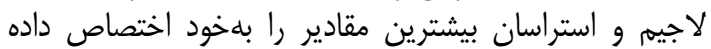

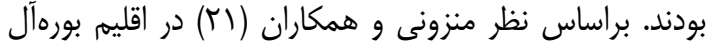

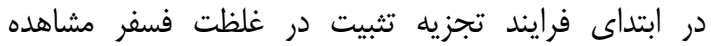

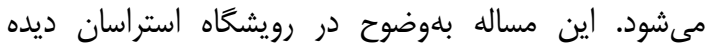

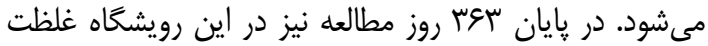

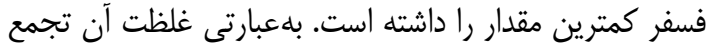

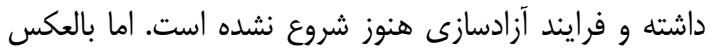

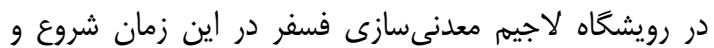

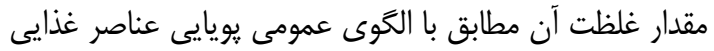

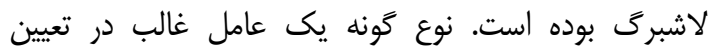

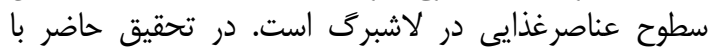

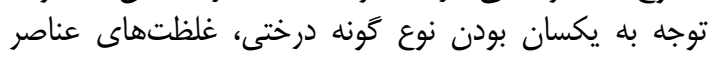

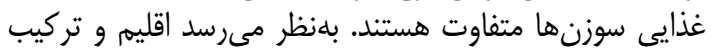


نهايى تجزيه در رويشكاههاى لاجيهم و استراسان نشان داد كه

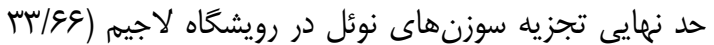

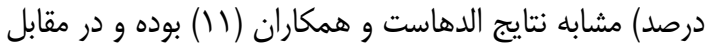

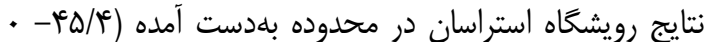

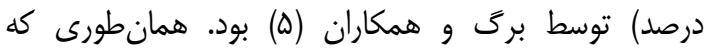

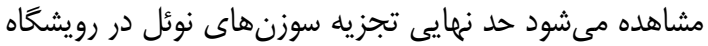

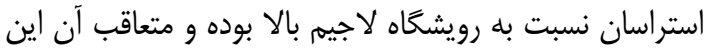

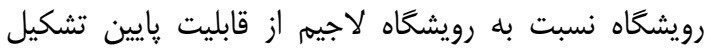

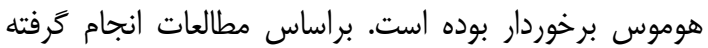

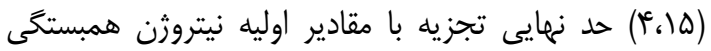

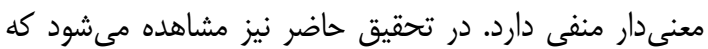

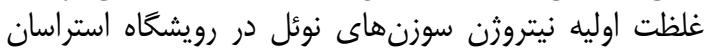

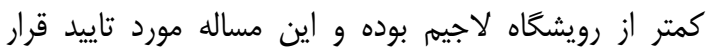

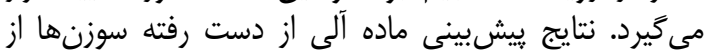

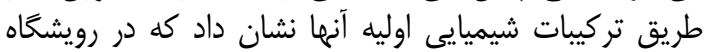

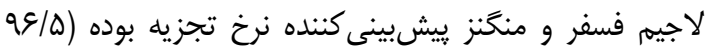

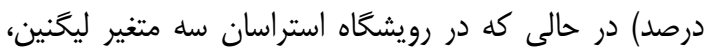

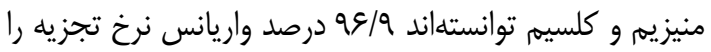

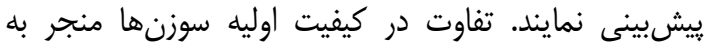

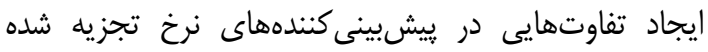

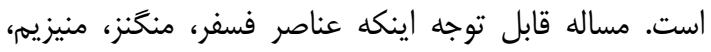

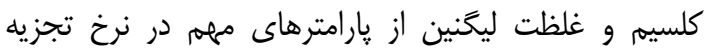

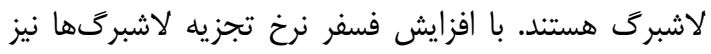

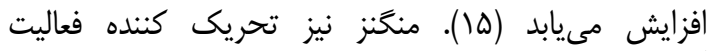

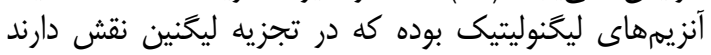

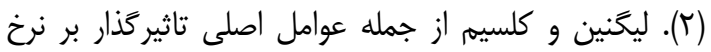

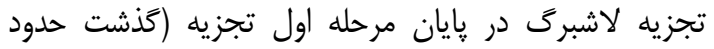

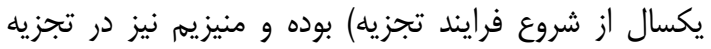

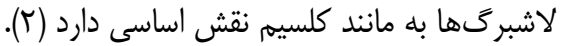

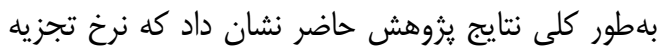

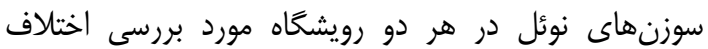

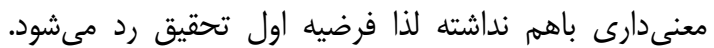

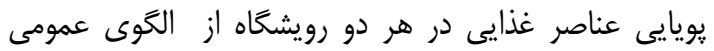

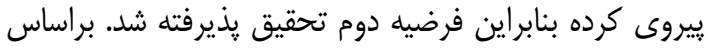

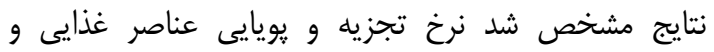

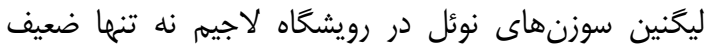

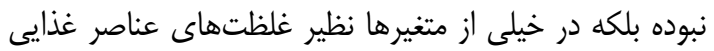

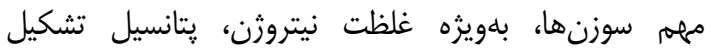

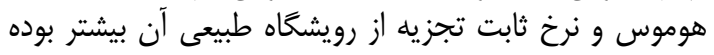

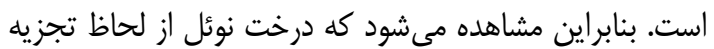

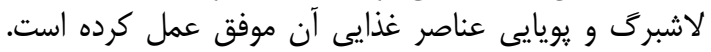

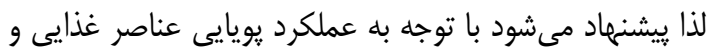

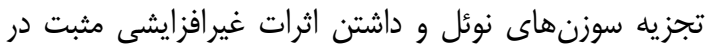

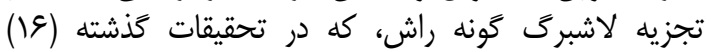

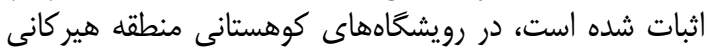

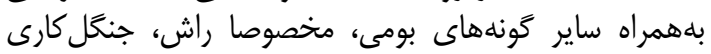

عمومى يويايى نيتروزن نشان مىدهد كه نيتروزن در ابتدا

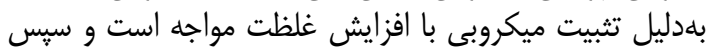

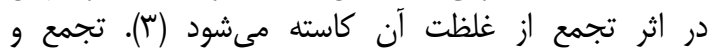

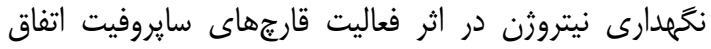

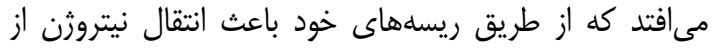

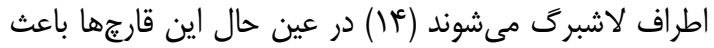

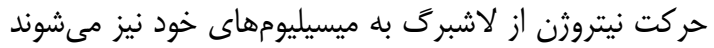

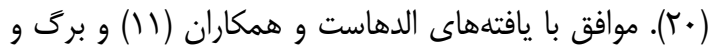

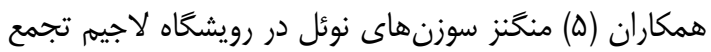

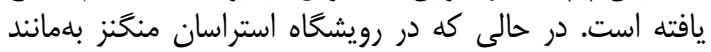

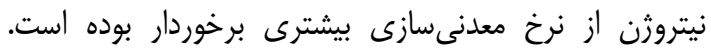

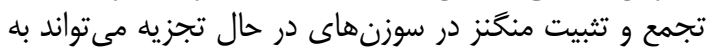

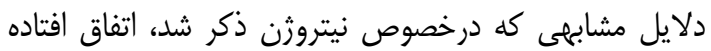

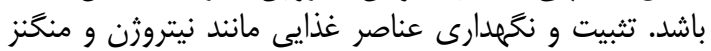

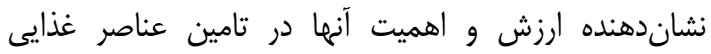

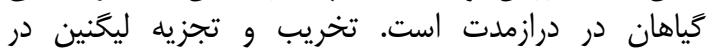

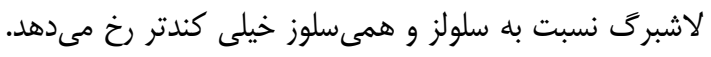

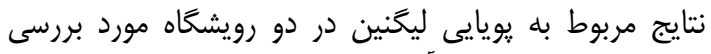

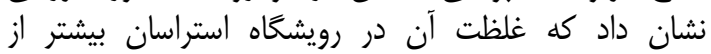

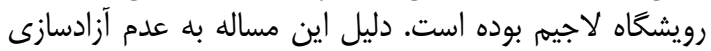

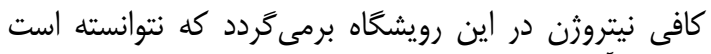

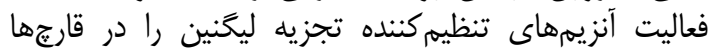

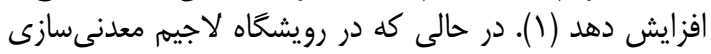

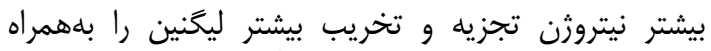

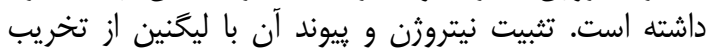

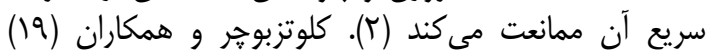

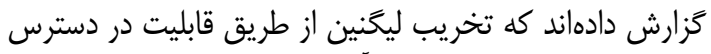

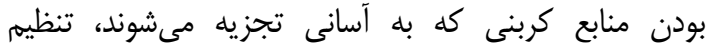

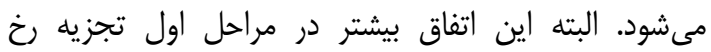

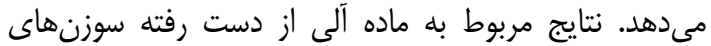

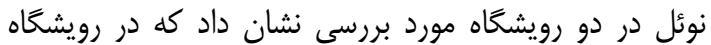

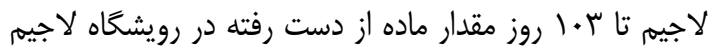

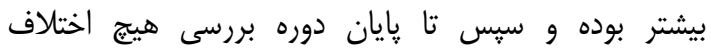

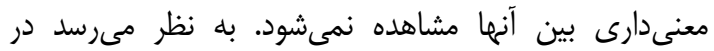

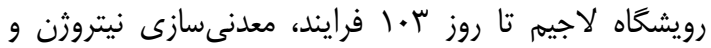

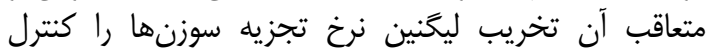

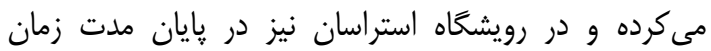

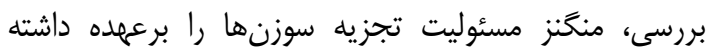

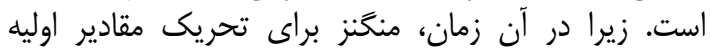

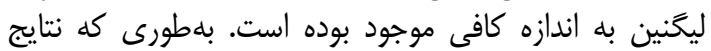

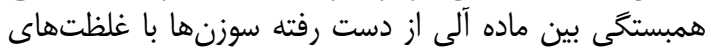

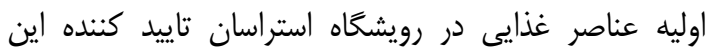

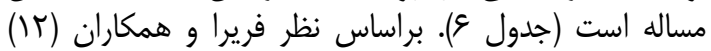

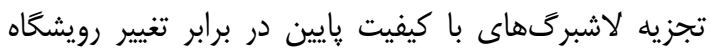

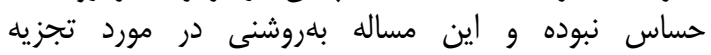

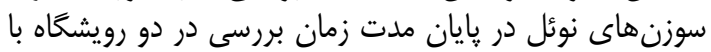
اقليم متفاوت مشاهده مى شود. مقادير محاسبه شده بران براى حرد حد 

, In litter decomposition: a guide to carbon and nutrient turnover. Elsevier, London, $421 \mathrm{pp}$.

2. Berg, B. and C. McClaugherty. 2008. Plant litter: decomposition, humus formation, carbon sequestration. Springer-Verlag Berlin Heidelberg.

3. Berg, B. and C. McClaugherty. 2014. Plant litter: decomposition, humus formation, carbon sequestration. 3rd ed. Springer-Verlag, Berlin Heidelberg.

4. Berg, B., A. De Marco, M. Davey, B. Emmett, S. Hobbie, C. Liu, C. McClaugherty, L. Norell, M.B. Johansson, F. Rutigliano, L. Vesterdal and A. Virzo De Santo. 2010. Limit values for foliar litter decomposition - pine forests. Biogeochemistry, 100: 57-73.

5. Berg, B., B. Erhagen, M.B. Johansson, L. Vesterdal, M. Faituri, P. Sanborn and M. Nilsson. 2013. Manganese dynamics in decomposing needle and leaf litter - a synthesis. Canadian Journal of Forest Research, 43: 1127-1136.

6. Berg, B., K.T. Steffen and C. McClaugherty. 2007. Litter decomposition rate is dependent on litter $\mathrm{Mn}$ concentrations. Biogeochemistry, 82(1): 29-39.

7. Cleveland, C.C., S. Reed, A. Keller, D. Nemergut, S. O’Neill, R. Ostertag and P. Vitousek. 2014. Litter quality versus soil microbial community controls over decomposition: a quantitative analysis. Oecologia, 174(1): 283-294.

8. Cotrufo, M.F., M.D. Wallenstein., C.M. Boot, K. Denef and E. Paul. 2013. The Microbial EfficiencyMatrix Stabilization (MEMS) framework integrates plant litter decomposition with soil organic matter stabilization: Do labile plant inputs form stable soil organic matter? Global Change Biology, 19: 988995.

9. Datry, T., R. Corti, C. Claret and M. Philippe. 2011. Flow intermittence controls leaf litter breakdown in a French temporary alluvial river: the "drying memory". Aquatic Sciences, 73: 471-483.

10. Delgado-Baquerizo, M., P. García-Palacios, R. Milla, A. Gallardo and F.T. Maestre. 2015. Soil characteristics determine soil carbon and nitrogen availability during leaf litter decomposition regardless of litter quality. Soil Biology and Biochemistry, 81: 134-142.

11. Eldhuset, T.D., O.J. Kjønaas and H. Lange. 2017. Decomposition rates and nutrient dynamics of Picea abies needles, twigs and fine roots after stem-only harvesting in eastern and western Norway. Plant Soil, 418: 357-375.

12. Ferreiraa, V., J. Korichevab, J. Pozoc and A.S.M. Graçaa. 2016. A meta-analysis on the effects of changes in the composition of native forests on litter decomposition in streams. Forest Ecology and Management, 364: 27-38.

13. Freschet, G. T., R. Aerts and J.H.C. Cornelissen. 2012. Multiple mechanisms for trait effects on litter decomposition: moving beyond home-field advantage with a new hypothesis. Journal of Ecology, 100 (3): 619-630.

14. Frey, S.D., E.T. Elliott, K. Paustian and G.A. Peterson. 2000. Fungal translocation as a mechanism for soil nitrogen inputs to surface residue decomposition in a no-tillage agro ecosystem. Soil Biology and Biochemistry, 32: 689-698.

15. Ghasemi Aghbash, F. and M. Zarafshar. 2018. Leaf litter Decomposition and Nutrient Dynamics of Persian Oak (Quercus brantii Lindl.) in the Northern Zagros Forests (Case Study: Chahar Zabar forests of Kermanshah). Iranian Journal of Forest, 10(3): 347-359 (In Persian).

16. Ghasemi Aghbash, F., GH.A. Jalali, V. Hosseini, S.M. Hosseini and B. Berg. 2012. Nutrient dynamic of Norway spruce (Picea abies (L) Karst) litter mixed with litter of Beech (Fagus orientalis lipsky), Alder (Alnus subcordata C.A.Meyer) and Maple (Acer velutinum Boiss.) in pure Norway spruce plantation of Lajim site. Iranian Journal of Forest and Poplar Research, 20(2): 286-298 (In Persian).

17. Ghasemi Aghbash, F., GH.A. Jalali, V. Hosseini and S.M. Hosseini. 2014. Assessment of Home Field Advantage (HFA) of Litter Decomposition in Beech and Alder Sites and in Norway spruce Plantation of Lajim Region. Iranian Forests Ecology, 2(3): 13-25 (In Persian).

18. Gulis, V., V. Ferreira and M.A.S. Graça., 2006. Stimulation of leaf litter decomposition and associated fungi and invertebrates by moderate eutrophication: implications for stream assessment. Freshwa. Biol, 51: 1655-1669.

19. Klotzbücher, T., K. Kaiser, G. Guggenberger, C. Gatzek and K. Kalbitz. 2011. A new conceptual model for the fate of lignin in decomposing plant litter. Ecology, 92: 1052-1062.

20. Lindahl, B.D., K. Ihrmark, J. Boberg, S. Trumbore, P. Högberg, J. Stenlid and R.D. Finlay. 2007. Spatial separation of litter decomposition and mycorrhizal nitrogen uptake in boreal forests, New Phytologist, 173: 611-620.

21. Manzoni, S., J.A. Trofymow, R.B. Jackson and A. Porporato. 2010. Stoichiometric controls on carbon, nitrogen and phosphorus dynamics in decomposing litter. Ecological Monographs, 80: 89106.

22. Parton, W., W.L. Silver, I.C. Burke., L. Grassens, M.E. Harmon, W.S. Currie, J.Y. King, E.C. Adair, L.A. Brandt and S.C. Hart., 2007. Global-scale similarities in nitrogen release patterns during longterm decomposition. Science, 315 (5810): 361-364.

23. Verne, I.K. 2017. Decomposition of Beech and Spruce Litter in Neighboring Beech and Spruce Forests. Master's Thesis, Faculty of Environmental Sciences and Natural Resource Management, Norwegian University of Life Sciences, 29 pp.

24. Young, R.G., C.D. Matthaei and C.R. Townsend. 2008. Organic matter breakdown and ecosystem metabolism: functional indicators for assessing river ecosystem health. Journal of the North American Benthological Society, 27(3): 605-625. 


\title{
Nutrient Dynamics and Decomposition rate of Norway Spruce Needles in Stråsan and Lajim Stands
}

\author{
Farhad Ghasemi Aghbash' ${ }^{1}$ and Björn Berg ${ }^{2}$
}

\author{
1- Assistant Professor, Department of Range and Watershed Management, Faculty of Natural Resources and \\ Environment, Malayer University, Malayer, Iran, (Corresponding author: f.ghasemi@ malayeru.ac.ir) \\ 2- Professor, Department of Forest Sciences, Faculty of Agriculture and Forestry, University of Helsinki, Helsinki, \\ Finland \\ Received: January 28, $2019 \quad$ Accepted: February 12, 2019
}

\begin{abstract}
Habitat change leads to differences in the rate of decomposition and nutrient dynamics of leaflitters, which has many effects on the controlling factors of the decomposition process. In the present study, the rate of decomposition and nutrient dynamics of Norway spruce were evaluated for 363 days in the two forestation sites in the natural and foreign habitats, Stråsan and Lajim. Nutrients such as nitrogen, phosphorus, potassium, calcium, magnesium, manganese and lignin, as well as Limit value, constant coefficient of decomposition and production capacity of humus were investigated using standard methods in both habitats. Nutrient and lignin concentrations were measured individually in each country using the same measurement method. The results showed that the initial quality of needles, except for calcium and manganese, in Lajim habitat (the concentrations of nutrients in nitrogen, phosphorus, potassium and magnesium were $12.63,1.23,9.85$, and $1.51 \mathrm{mg} / \mathrm{g}$ ) was better than Stråsan (the concentrations of calcium and manganese were 13.4 and $1.38 \mathrm{mg} / \mathrm{g}$ ). The dynamics pattern of nutrients in two habitats was similar during the study period, but in 363 day, there were significant differences $(p<0.05)$ in the concentrations of manganese and phosphorus. The remaining weight in two habitats at the end of the period did not show any significant difference (Lajim and Stråsan habitats were $77.69 \%$ and $77.92 \%$ respectively). The constant coefficient of decomposition and production capacity of humus in Lajim habitat was higher (respectively, $0.24 \%$ per day and 66 fractions) than Strassan habitat (respectively, $0.1 \%$ per day and 55 fractions). Based on the stepwise regression, in the Lajim habitat the concentrations of phosphorus and manganese and in the Stråsan the concentrations of lignin, magnesium and calcium were the only variables which explained mass loss variation. In general, the results of this study showed that Norway spruce in Lajim habitat was successful in the view point of the decomposition and nutrient dynamism and in the compared to its natural habitat, and could be used in the Hyrcanian mountain forest for reforestation projects.
\end{abstract}

Keywords: Boreal forests, Decomposition rate, Habitat change, Leaflitter quality, Norway spruce 